\title{
An endemic area of Dirofilaria immitis seropositive dogs at the eastern foothills of Mt Olympus, Northern Greece
}

\author{
M. LEFKADITIS ${ }^{1,2}$, S. KOUKERI ${ }^{2}$, V. COZMA $^{3}$ \\ ${ }^{1}$ Veterinary Faculty, Laboratory of Microbiology and Parasitology, Karditsa, Greece, E-mail: mleuka@otenet.gr; \\ ${ }^{2}$ Veterinary Clinic, Delfon 111, 54644 Thessaloniki, Greece; ${ }^{3}$ University of Veterinary Medicine, Department of \\ Parasitology, Cluj-Napoca, Romania
}

\begin{abstract}
Summary
Following an examination conducted on a population of three hundred and forty-one dogs living on the eastern foothills of Mt Olympus in Northern Greece, $17.9 \%$ were found to be seropositive for the Dirofilaria immitis specific antigen. These results indicate that the region is an endemic area for the above-mentioned parasitosis in dogs. Serum samples were examined using the PetChek kit Snap (IDDEX Laboratories, ELISA, Portland USA) according to the manufacturer's instructions.

With respect to gender, age and type of coat, the statistical analysis has shown that the prevalence of seropositive results is significantly higher $(\mathrm{P}<0.05)$ among male dogs, older dogs and short-haired dogs. As regards breed and size, the same study has recorded a higher prevalence in mixed breed and small-sized dogs.
\end{abstract}

\section{Introduction}

Heartworm infection which is caused by the nematode parasite Dirofilaria immitis, is a common and serious disease, affecting dogs in tropical, subtropical and temperate regions of the world (Quinn et al., 1997; McCall et al., 2004). It is a frequent parasite in dogs as well as other animals, such as foxes, cats, bears, wolves and horses, and is rarely found in humans (Haralampidis, 2003; Bailey et al., 1990).

The clinical signs of dirofilariosis are related to the stage in the lifecycle of the worm that we are dealing with, the severity of the infection and how the host has responded to the infection. Its pathology is not only influenced by the number of worms but also by the stress caused by the high blood flow. Young adult worms are often found in the branches of the pulmonary arteries and adult worms are usually located in the right ventricle and the main pulmonary arteries (Quinn et al., 1997). Most affected animals present signs of right-sided heart failure or vena cava syndrome (Quinn et al., 1997). Other recorded symptoms include exercise intolerance, weakness, coughing, and pneumonitis (Haralampidis, 2003; Mehlhorn, 2001; Şahal et al., 1997; Kitagawa et al., 1990). No clinical signs have been associated with circulating microfilariae (Haralampidis, 2003).

The pathogenicity of $D$. immitis is well-known, qualifying the heartworm disease as one of the most serious veterinary diseases where prophylactic treatment is recommended (McCall et al., 2004).

The aim of this study is to record its prevalence amongst dogs living on the eastern foothills of Mt Olympus in Greece, since this infection is considered highly serious for dogs and is known to be a zoonosis. Furthermore, it is important to provide information and try to prevent the possibility of the infection spreading to even more dogs that belong to the area's inhabitants and/or visitors. An extensive movement of dogs across countries and continents has contributed to a spreading of the infection to new areas with vectors and favorable conditions (Schrey \& Trautvetter, 1998).

\section{Materials and methods}

In the present study, 341 serum samples from dogs (Table 1) that spent their whole life living in the urban area of the eastern foothills of Mt Olympus were examined for the presence of the D. immitis antigen. Blood samples were taken via cephalic vein venipuncture.

Specific adult worm antigen tests were used for the study to detect specific antigens from adult female heartworms. These are very efficient in identifying canine heartworm infection (Steere, 1989). Currently, assays are available as in-clinic tests, and also in many veterinary diagnostic laboratories. In this study, the PetChek kit Snap (IDDEX Laboratories, ELISA, Portland USA) was used, according to the manufacturer's instructions. This test is an enzyme immunoassay designed to detect the presence of circulating 
antigens from an adult female in serum or plasma.

The study was carried out between October 2006 and October 2008. A statistically significant analysis of the variation in the seropositive rate in relation to breed, gender, age, size and type of coat was conducted by using the Chi-square test, and the significant difference was $\mathrm{P}<$ 0.05 .
In the present paper, it is important to note that the estuaries of four rivers (Galikos, Axios, Loudias and Aliakmon) are located north of the region under study. Several rice crops exist close to this area, thus creating a favourable site for the development of mosquitoes (due to the stagnant waters). The geographical distribution of the above-mentioned infection is associated with the availab-

Table 1. Classification of the examined dogs according to gender, age, breed, size coat

\begin{tabular}{ccccccccccc}
\hline $\begin{array}{c}\text { Total } \\
\text { number }\end{array}$ & Males & Females & $\begin{array}{c}\text { Under } \\
4 \text { yrs }\end{array}$ & $\begin{array}{c}\text { Over } \\
4 \text { yrs }\end{array}$ & $\begin{array}{c}\text { Mixed } \\
\text { breed }\end{array}$ & $\begin{array}{c}\text { Pure } \\
\text { breed }\end{array}$ & $\begin{array}{c}\text { Small } \\
\text { size }\end{array}$ & $\begin{array}{c}\text { Large } \\
\text { size }\end{array}$ & $\begin{array}{c}\text { Short } \\
\text { coat }\end{array}$ & $\begin{array}{c}\text { Long } \\
\text { coat }\end{array}$ \\
\hline 341 & 189 & 152 & 94 & 247 & $\mathbf{2 2 0}$ & 121 & 102 & 239 & 140 & 241 \\
\hline
\end{tabular}

\section{Results and discussion}

From the total population of 341 dogs, 61 (17.9\%) were found to be seropositive for the Dirofilaria immitis special antigen (Table 2).

Individual serological tests were carried out to identify specific antigens of $D$. immitis in the bloodstream. False negative test results mainly occur in the case of light infections, or in the absence of adult female worms (Hoover, 1996). Antigen tests are currently recommended by the American Heartworm Society for primary screening and confirmation of heartworm infection in dogs (Anon, 1995; Weil et al., 1985). ility of the intermediate hosts, the mosquitoes (Otto, 1969). Environmental conditions, such as humidity, stagnant waters and warm temperatures, influence the mosquito population (Quinn et al., 1997), whose highest prevalence occurs in river valleys and humid areas (Muro et al., 1999). Several epidemiological studies have shown that this infection is widely distributed in Africa, Asia, Australia, Latin America and in Mediterranean countries (Cringoli et al., 2001; Montoya et al., 1998). At present, dirofilariosis is not endemic in many north-western European countries (Schrey, 1996; Greeve et al, 1983). All cases reported in Great Britain, the Netherlands, Sweden, Austria, and Germany, had been previously imported from endemic areas

Table 2. Classification of the infected dogs according to gender, age, breed, size, coat

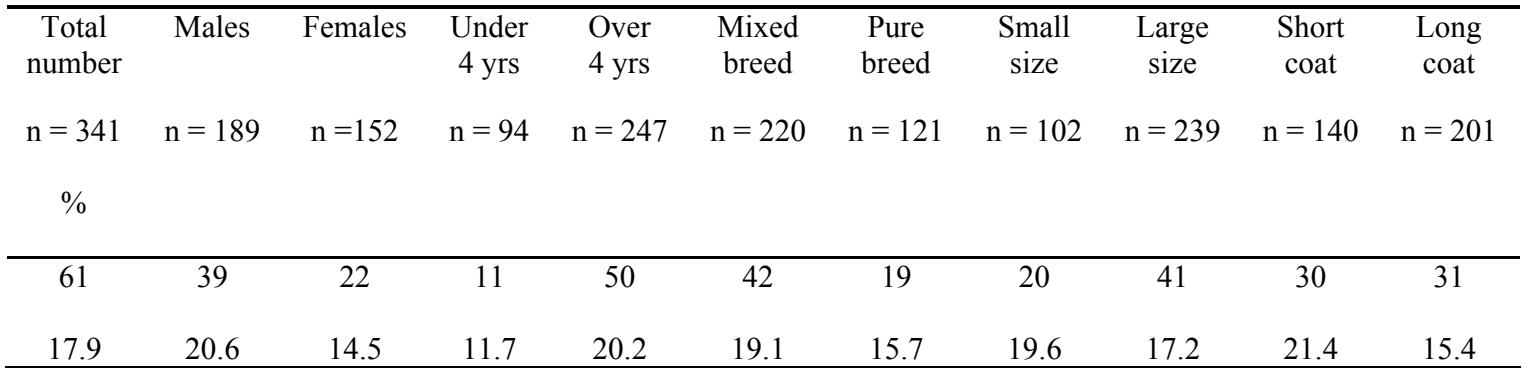

ELISA antigen tests detect specific circulating proteins released by the reproductive tract of the mature female worm and a strongly positive antigen test is normally correlated with a heavy heartworm infestation (Shaw \& Day, 1995). Specificity is close to $100 \%$ for all the available kits (Shaw \& Day, 1995). Small worm burdens, the presence of immature females or male-only infections are common causes of low antigen titles and false negative results (Hoover et al., 1990). Hoover et al., (1990) found that the PetChek test gave no false positive. Öge et al., (2003) reported that the false negative rate for the PetChek test is $7.7 \%$. Courtney and Zeng (2001), in comparing the PetChek test with five others, recorded a significantly higher sensitivity in the former as opposed to the other tests. The antigen levels become undetectable within $8-$ 12 weeks following adulticidal therapy (Shaw \& Day, 1995).
(Bucklar et al., 1998; Zahler et al., 1997; Schrey 1996). Recently, the infestation has spread to colder areas where mosquitoes also exist, such as Bretagne in France (Doby et al., 1986), Switzerland (Bucklar et al., 1998), and the northern provinces of Italy (Rossi et al., 1996, Genchi et al., 1995). Dirofilaria immitis is by far the most important filarioid parasite affecting domestic animals in North America (Bowman et al., 2003). Heartworm disease is also an important parasitosis in dogs in various Mediterranean countries, including Greece (Haralampidis, 2003), where it is regarded as a relatively common disease in the local daily clinical practice.

A closer examination of certain Mediterranean countries points to the following observations: in Spain, the distribution of heartworm infection varies (Ortega-Mora et al., 1991). The highest rates are found in the southern provinces of Huelva (36.7 \%), Cadiz (12.0\%) and Badajoz (8.0 
\%). The Canary Islands of Tenerife $(20.0 \%)$ and Las Palmas (36.0 \%) are also endemic (Guerrero et al., 1992), and a more recent report (Montoya et al., 1998) estimates that $58.9 \%$ of dogs in the Canary Islands are infected. Another recent survey carried out in the Baix Llobregat area of Barcelona, showed that $12.8 \%$ of dogs were positive (Aranda et al., 1998). Moreover, other surveys indicate that the infection is spreading into Northern provinces. Guerrero et al., (1995) reported an increased prevalence in the region of Cataluna, from $0.38 \%$ in 1989 to just over 5 $\%$ in 1995. In Portugal, an epidemiological survey reports a prevalence of heartworm infection in Ribatejio (16.7\%), Alentejo (16.5\%), Algarve (12\%) and the Islands of Madeira (30\%) (Araujo, 1996). In France, the infection is found mainly along the Mediterranean coast and positive dogs have been found predominantly in Bouches du Rhone, Vancluse and Corse Island, and to a lesser extent in Haute-Garonne and Dordogne (Guerrero et al., 1995). In Italy, there is a reported prevalence of $22 \%$ in Piedmont (Rossi et al., 1993), $48 \%$ in Lombardy (Genchi et al., 1998), $64 \%$ in Emilia Romagna (Poglayen et al., 1992), $55 \%$ in Veneto and Venezia Giulia (Poglayen et al., 1996). The reported prevalence in Greece was $10 \%$ in the Macedonia region (Papazahariadou et al., 1994) and rose to $34 \%$ a few years later in the same region (Founta et al., 1999). Nevertheless, a very low prevalence has been recorded in the Attica region (Diaku, 2001). Limited data is available from the relevant literature regarding the prevalence of the infection in other Balkan countries. It ranges between $2 \%$ and $17 \%$ in Slovenia (Brglez \& Senk, 1987), Bulgaria (Georgieva et al., 1999), and Turkey (Doganay \& Biyikoglu, 1992; Öge et al., 2003) and increases to $65 \%$ in Romania (Olteanu, 1996). A survey in 2003 revealed that $9.32 \%$ of 280 domestic dogs were infected in Ankara and in the surrounding vicinity (Öge et al., 2003). In another study, Oncel and Vural (2003) recorded a prevalence of $D$. immitis in $1.52 \%$ of stray dogs in Istanbul.

Dog and its close relatives are the natural hosts, but the infection also occurs in cats (Calvert \& Mandell, 1982) and ferrets. Other wild animals living on Mt Olympus may also play an important role in the prevalence of the $D$. immitis infection as a potential reservoir. In California, a survey involving coyotes showed prevalence in $19.4 \%$ of them (Sacks, 1998). In Australia there is a reported prevalence of $6.4 \%$ in the red fox population (Marks and Bloomfield, 1998). In Spain, in the Ebro Valley, $13 \%$ and $1.7 \%$ of foxes, captured in irrigated habitats and semi-arid habitats respectively, were found to be infected (Gortazar et al., 1998), while Segovia et al., (2001) reported a prevalence of $2.1 \%$ in wolves.

Human infection is abortive and results in radiographic changes, referred to as "coin lesions", which have been misinterpreted as representing neoplasia and can lead to unnecessary thoracic surgery (Bowman et al., 2003).

In the present study, a significant higher seroprevalence was observed in male dogs $(\mathrm{P}<0.05)$. Selbey et al., (1980) also found that male dogs faced a relatively higher risk of heartworm infection. Montoya et al., (1998) recorded that the frequency of infection is related to lifestyle, with male dogs becoming more frequently infected than female dogs. In a study of seroprevalence rates in males and females in Istanbul, no significant difference was noted between the two genders (Öge et al., 2003). Certain studies (Miterpákova et al., 2008; Selbey et al., 1999; Şahal et al., 1997; Kitagawa et al., 1990; Glickman et al., 1986) record a higher prevalence in male dogs rather than females; another study (Montoya et al., 1998) however, recorded that female dogs were more frequently infected.

In the present study, a significantly higher prevalence was recorded in dogs over 4 years of age. Other researchers (Montoya et al., 1998) have also indicated that age is an important risk factor, determined by the period of exposure to the endemic area. Quinn et al., (1997) reported that the prevalence in dogs over 5 years of age is higher. Therefore, older animals have a higher prevalence compared to young dogs (Fan et al., 2001; Öge et al., 2003; Graham, 1974), although there are some reports that do not consider age to be an important factor (Thrasher et al., 1968; Martin et al., 1985). Şahal et al., (1997) and Glickman et al., (1986) have recorded that amongst elderly dogs, those aged 8 to 9 years have a decreased risk of infection, since the immune system of this specific age group prevents the maturation of the parasite. The increased prevalence in older dogs can be the result of two features in this host-parasite relationship; firstly, the lack of any age resistance related to the dogs and, secondly, longer exposure to the risk factor, i.e. the mosquito (Theis et al., 1999; Öge et al., 2003).

Regarding the type of coat, the present study has recorded a significantly higher prevalence $(\mathrm{P}<0.05)$ in short-haired dogs (less $4 \mathrm{~cm}$ long). On the contrary, Miterpáková et al., (2008) record a significantly higher prevalence in longhaired dogs in Slovakia.

The results of this study point to the fact that there is a need to provide information to dog owners residing in or visiting this specific region regarding the fact that prophylactic treatment is obvious in order to minimize the spreading of the infection and should be administered to their dogs for the disease in question. Otherwise, dogs that have not received such a treatment should undergo testing in order to ascertain whether they have been infected, so that suitable treatment is provided in order to stop any further spreading of the disease.

\section{References}

ANON (1997): American Heartworm Society recommended procedures for the diagnosis, prevention and management of heartworm (Dirofilaria immitis) infection in dogs. In Heartworm Symp. Proc. Canine Pract., 22: 8 - 15

Aranda, C., Octavi, P., Eritja, R., Castella, J. (1998): Canine filariasis. Importance and transmission in the Baix Llobregat area, Barcelona (Spain). Vet. Parasitol., 77: 267 - 275. DOI: 10.1016/S0304-4017(98)00109-5

Araujo, A. M. (1996): Canine and human Dirofilaria immitis infections in Portugal. A review. In Proc. VIIth EMOP. Parassitologia, 38 (Suppl. 1-2), 366-371 
Bailey, T. S., Sohrabi, A., Roberts, S. S. (1990): Pulmonary coin lesions caused by Dirofilaria immitis. J. Surg. Oncol., 44: 268 - 272. DOI: 10.1002/jso.2930440415

BOWMAN, D. D. (2003): Parasitology for veterinarians. Philadelphia, U. S. A., W. B. Saunders Company, 414 pp. Brglez, J., SenK, L. (1987): Dirofilaria immitis (Leidy, 1856) Railliet et Henry, 1911, in dog. In Zbor. Bioteh. Fak. Univ. E. Kardelja Ljubljani. Veterinarstvo, 24: $69-72$

Bucklar, H., Scheu, U., Mossi, R., DePlazes, P. (1998): Is dirofilariosis in dogs spreading in south Switzerland? Schweiz. Arch. Tierheilkd., 140: 255 - 260

Calvert, C. A., Mandell, C. P. (1982): Diagnosis and management of feline heartworm disease. J. Am. Vet. Med. Assoc., 180: 550 - 552

Courtney, C. H., ZENG, Q. Y. (2001): Comparison of heartworm antigen test kit performance in dogs having low heartworm burdens. Vet. Parasitol., 96: 317 - 322. DOI: 10.1016/S0304-4017(01)00374-0

Cringoli, G., Rinaldi, L., Veneziano, V., CAPelli, G. (2001): A prevalence survey and risk analysis of filariosis in dogs from the Mt. Vesuvius area of southern Italy. Vet. Parasitol., 102: 243 - 252. DOI: 10.1016/S03044017(01)00529-5

DIAKU, A. (2001): The prevalence of canine dirofilariosis in the region of Attiki. Bull. Hellenic. Vet. Med. Soc., 52: $152-156$

Doby, J. M., Guiguen, C., Lefevre, R. (1986): Présence de Dirofilaria immitis (Leidy, 1856) chez le chien en Bretagne. Bull. Soc. Franc. Parasitol., 4: $51-54$

Doganay, A., Biyikoglu, G. (1992): The Filarial Nematodes in dogs. Etlik. Vet. Mikrob. Derg., 7: 127 - 139 (In Turkish)

FAn, C. K., Su, K. E., Lin, Y. H., LiaO, C. W., Du, W. Y., CHIOU, H. Y. (2001): Seroepidemiologic survey of Dirofilaria immitis infection among domestic dogs in Taipei City and mountain aboriginal districts in Taiwan (1998 1999). Vet. Parasitol., 102: 113 - 120. DOI: 10.1016/S0304-4017(01)00511-8

Founta, A., TheOdoridis, Y., Frydas, S., ChliounAKIS, S. (1999): The presence of filarial parasites of dogs in Serrae province. Bull. Hellenic. Vet. Med. Soc., 50: 315 - 320 Genchi, C., Solari Bazano, F., BAndi, C., Di Sacco, B., Venco, L., Vezzoni, A., CANCRINI, G. (1995): Factors influencing the spread of heartworm in Italy; interaction between Dirofilaria immitis and Dirofilaria repens. In: Soll, M. D., KNIGHT, D. H. (Eds) Proc. Heartworm Symp. '95, American Heartworm Society, Batavia., IL: $65-71$

Genchi, C., Solari Basano, F., Marrone, R. V., PetruschKe, G. (1998): Canine and feline heartworm infection with special emphasis on Italy. In: SOLL, M. D., Knight, D. H. (Eds) Proc. Heartworm Symp. '98, American Heartworm Society, Batavia: 75 - 82

Georgieva, D. A., Ivanov, A. I., Prelesov, P. N. (1999): Studies on the parasitic fauna in stray dogs in the Stara Zagora region. Bulgarian J. Vet. Med., 2: $121-124$

Glickman, L. T, Grieve, R. B., SChantz, P. M. (1986): Serologic pattern of zoonotic pulmonary dirofilariasis. Am. J. Med.; 80: 161 - 164. DOI: 10.1016/0002-9343(86)90003-3
Gortazar, C., Villafuerte, R., Lucientes, J., FERNANDEZ-DE-LUCO, D. (1998): Habitat related differences in helminth parasites of red foxes in the Ebro valley. Vet. Parasitol., 15: 75 - 81. DOI: 10.1016/S0304-4017(98) 00192-7

GraHAM, J. M. (1974): Canine filariasis in North Eastern Kansas. J. Parasitol., 60: 322 - 326. DOI: 10.2307/3278475 Greeve, R. B, LoK, J. B., Glickman, L. T. (1983): Epidemiology of canine heartworm infection. Epidemiol. Rev., 5: $220-246$

Guerrero, J., Ducos De la Hitte, J., Genchi, C., Rojo, F., Gomez-Bautista, M., Carvalho Valera, M., Labar-The, N., Bordini, E., Gonzales, G., Mancebo, O., Patino, F., Uribe, L. F., SAmano, R. (1992): Update on the distribution of Dirofilaria immitis in dogs from Southern Europe and Latin America. In: SolL M. D. (Ed) Proc. Heartwom Symp. '92, American Heartworm Society, Batavia, IL: $31-37$

Guerrero, J., Rodenas, A., Gutierez Galindo, J., FloRIT, F. (1995): The extension of the prevalence of Dirofilaria immitis in Cataluna, Spain. In: SolL, M. D., KNIGHT, D. H. (Eds) Proc. Heartworm Symp. '95, American Heartworm Society, Batavia., IL: 73 - 77

Haralampidis, S. T. (2003): Parasitic diseases of animals and humans. University Studio Press. Thessaloniki.

Hoover, J. P., CAmpbell, G. A., Claypool, P. L., Mullins, S. B. (1996): Comparison of eight diagnostic blood tests for heartworm infection in dogs. Canine Pract. 21: 11 - 19

Kitagawa, H., Sasaki, Y., Ishihara, K., Hirano, Y. (1990): Contribution of live heartworms harboring in pulmonary arteries to pulmonary hypertension in dogs with dirofilariasis. Jpn. J. Vet. Sci., 52: $1211-1217$

MArks, C. A., Bloomfield, T. E. (1998): Canine heartworm (Dirofilaria immitis) detected in red foxes (Vulpes vulpes) in urban Melbourne. Vet. Parasitol., 78: 147 - 154. DOI: 10.1016/S0304-4017(98)00131-9

Martin, T. E., Collins, G. H. (1985): Prevalence of Dirofilaria immitis and Dipetalonema reconditum in greyhounds. Aust. Vet. J., 62: 159 - 163. DOI: 10.1111/j.17510813.1985.tb07278.x

McCall, J. W., Guerrero, J., Genchi, C., Kamer, L. (2004): Recent advances in heartworm disease. Vet. Parasitol., 125: 105 - 130. DOI: 10.1016/j.vetpar.2004.05.008

MeHlhoRn, H. (2001): Encyclopedic Reference of Parasitology. 2nd ed., Disease, Treatment, Therapy. Düsseldorf, Germany, 100 - 101

MiterpákovÁ, M., Antolová, D., Hurníková, Z., DuBINSKÝ, P. (2008): Dirofilariosis in Slovakia - a new endemic area in Central Europe. Helminthologia , 45, 1: 20 - 23. DOI: 10.2478/s11687-008-0003-6

Montoya, J. A., Morales, M., Ferrer, O., Molina, J. M., CorberA, J. A. (1998): The prevalence of Dirofilaria immitis in Gran Canaria, Canary Islands, Spain (1994 1996). Vet. Parasitol., 75: 221 - 226. DOI: 10.1016/S0304-4017(97)00175-1

Muro, A., Genchi, C., Cordero, M., Simon, F. (1999): Human dirofilariasis in the European Union. Parasitol. Today, 15: 386 - 389. DOI: 10.1016/S0169-4758(99)01496-9 
Öge, H., Doganay, A., ÖGE, S., YildiRim, A. (2003): Prevalence and distribution of Dirofilaria immitis in domestic dogs from Ankara and vicinity in Turkey. Dtsch. Tierärztl. Wochenschr., 110: $69-72$

Olteanu, G. (1996): Dirofilariosis in man and animals in Romania. Parasitologia, 38: 360

ÔNCEL， T., VURAL， G. (2003): Seroprevalence of Dirofilaria immitis in Stray Dogs in Instabul and Izmir. Turk. J. Vet. Anim Sci., 29: 785 - 789

Ortega-Mora, L. M., Gomez-Bautista, M., RojoVASQUez, F., Rodenas, A., GuerRero, J. (1991): Survey on the prevalence of canine filariasis in Spain. Prev. Vet Med., 11: 63 - 68. DOI: 10.1016/S0167-5877(05)80045-5

Отто, G. F. (1969): Geographical distribution, vectors and life-cycle of Dirofilaria immitis. J. Am. Vet. Med. Assoc., 154: 370 - 373

PapaZAhariadou, M. G., Koutinas, A. F., Rallis, T. S., HARALAMPIDIS, S. T. (1994): Prevalence of microfilaemia in episodic weakness and clinically normal dogs belonging to hunting breeds. J. Helmintol., 68: $243-245$. DOI: 10.1017/S0022149X00014413

Poglayen, G., Martini, M., Bomben, L., Roda, R. (1992): An updating of the occurrence of canine heartworm disease in northern Italy. In Proc. VIth EMOP: 114 Quinn, P. J., Donnelly, W. J. C., CARTER, M. E., MARKEY, B. K. J., TORGERSON, P. R., BREATHNACH, R. M. S. (1997): Microbial and parasitic diseases of the dog and cat. U. S. A., W. B. Saunders Company.

Rossi, L., Pollono, F., Meneguz, P. G., Gribaudo, L., BALBO, T. (1996): An epidemiological study of canine filarioses in north-west Italy: what has changed in 25 years? Vet. Res. Comm., 20: 308 - 315. DOI: 10.1007/BF00366536 SACKS, B. N. (1998): Increasing prevalence of canine heartworm in coyotes from California. J. Wild Dis., 34: $386-389$
Şahal, M., ÖZlem, M., Tanyel, B., ÖCal, N., Sel, T. (1997): The biochemical changes in blood, urine and abdominal fluid in dogs infected by Dirofilaria immilis. Ankara Üniv. Vet. Fak. Derg., 44: 267 - 276

SCHREY, C. F. (1996): Epidemiologische Fallanalyse der kardiovaskularen Dirofilariose (Herzwurmerkrankung) bei Hunden in Deutschland. Dissertation for $\mathrm{PhD}$ in Veterinary Medicine, der Freien Universitat Berlin.

SCHREY, C. F., TrautvetTer, E. (1998): Canine and Feline heartworm disease-diagnosis and therapy. Waltham Focus, 8: $23-30$

Segovia, J. M., Torres, J., Miquel, J., Llaneza, L., FeliU, C. (2001): Helminths in the wolf, Canis lupus, from north-western Spain. J. Helmint., 75: 183 - 192

Selbey, L. A., CoRwin, R. M., HAYES, H. M. (1980): Risk factors associated with canine heartworm infection. $\mathrm{J} . \mathrm{Am}$. Vet. Med. Assoc., 176: 33 - 35

SHAW, E. S., DAY, J. M. (2005): Arthropod-borne infectious diseases of the dog and cat. Manson Publishing Ltd. London.

Theis, J. H., Stevens, F., Theodoropoulos, G., Ziedins, A. C. (1999): Studies on the prevalence and distribution of filariasis in dogs from Los Angeles County, California (1996 - 1998). Canine Pract., 24: 8-16.

THRASHER, J. P., GOULD, K. G., LYNCH, M. J., HARRIS, C. C. (1968): Filarial infections of dogs in Atlanta, Georgia. $J$. Am. Vet. Med. Assoc., 153: $1059-1062$

Weil, G. J., Malane, M. S., Powers, K. G., Blair, L. S. (1985): Monoclonal antibodies to parasite antigens found in the serum of Dirofilaria immitis-infected dogs. J. Immunol., 134: 1185 - 1191

ZAHLER, M., GLASER, B., GOTHE, R. (1997): Imported parasites in dogs: Dirofilaria repens and Dipetalonema reconditum. Tierarztl. Prax., 25: 388 - 392 